those of acute local fatigue, and there can be little doubt that this condition is a common cause of many of those chronic maladies which seem to result from overwork, and which are characterised by irregular muscular action. That some cases of writer's cramp, torticollis, and hammer. palsy, are due to chronic fatigue of the muscles employed, there can be little doubt. Duchenne and Mr. Brudenell Carter have pointed out how, in cases of short sight, the prolonged strain of the internal recti has caused troubles of vision and even cerebral symptoms; and quite lately Dr. C. B. Taylor, of Nottingham, has shown reason for including in the category of "fatigue diseases" a peculiar form of nystagmus occurring amongst miners, who try their eyes by working in the dark, and the author has little doubt that, attention having been directed to the symptoms and effects of fatigue, additional light on the subject will be forthcoming.

wimpole-street.

\section{CONCLUDING REPORT}

\section{CASE OF INNOMINATE ANEURISM.}

LIGATURE OF THE LEFT COMMON CAROTID ARTERY, FOR ANEURISM AT ITS BIFURCATION.

BY FREDERICK ENSOR, M.R.C.S., SURGEON TO PORT ELIZABETH HOSPITAT, SOUTH AFRICA.

The readers of The LanceT of February 6th last will have noticed the report of a case of innominate aneurism treated by ligature of the carotid and subclavian arteries simultaneously. As it may be considered one of some surgical interest, and an example of a mode of treatment as yet on its trial, I think it right to publish the ultimate result of the case.

The operation was performed on Sept. 8th, and up to date of last report the man was going on favourably. The subclavian wound had firmly healed, and there was but a little stain of discharge from a granulating spot in the line of the carotid insision. The patient had little or no pain, the impulse was less, the bruit was less marked, and there was very trifling impediment to his deglutition, and he was allowed to go about the ward.

On Oct. 24th he very imprudently went out of his room with simply his night-dress on, remaining some half an hour out of his bed in the cold. The next morning he was taken with shivering, and had rheumatic-like pains generally. The pulse rose to 95 , the impulse became very marked above the clavicle, and a little bleeding came on from the lowest part of the carotid wound. Ordered a mixture of carbonate of ammonia, chlorate of potash, and tincture of aconite, half a minim, every four hours.

Oct. 25th.-Pulse 88.

26 th.-Pulse 80 ; impulse less. No pain.

27th.-Pulse 80 .

28th.-Pulse 76. To take the mixture at eleven, four, and nine o'clock.

29th.-Pulse 76. Mixture at eleven and nine o'clock.

30th.-Pulse 75. Bowels too relaxed. To take two minims of tincture of aconite, twenty-five minims of chlorodyne, and one ounce of infusion of gentian, twice a day.

31st.-Pulse 92. Cough very troublesome last night, and after a paroxysm free hæmorrhage came on from carotid wound at 9 P.M. Applied lint soaked in tincture of iron, and strapping, and gave a dose of solution of morphia. This morning lies in a sleepy state. No more bæmorrhage; tumour pulsating forcibly; marked ogdema of left hand; some cedema of feet.

Nov. 1st.-Pulse 95. Hæmorrhage again last night after a bad fit of coughing.

2nd.-Pulse 96. No hæmorrhage.

3rd.-Pulse 96. Coughs up a tenacious mucus.

4.th.-Pulse 88 ; impulse feeble.

5th.-Pulse 86. Hæmorrhage at 5 o'clock this morning.

7th.-Pulse feeble. No particular pain in chest. Has

had a little oedema of right eyelid for the last two or three days, and to-day the cornea looks cloudy, and is apparently perishing.

9lh.-Cornea has given way; vitreous and lens escaped; eye collapsed. Face a little drawn to left; swallows without much difficulty.

10 th.-Hrmorrhage again at 8.30 when in the act of smoking; arrested by the same means as before. Has no difficulty of breathing if he turns his head to the right, but it comes on if he turns it to the left.

11th.-Pulse weak and intermitting; complains of no pain, but, putting his hands together, says " his breath is like that."

12th.-Died comatose at 10 o'clock this morning.

Necropsy, six hours after death-Body thin, but not emaciated. Base of neck above the collar-bones bulging, a plug of coagulum presenting at lower part of carotid wound. In removing the sternum and sternal end of clavicle careful dissection was needed to avoid tearing the parts immediately beneath. The ascending aorta was generally dilated, and arising from it was a semi-solid tumour, formed by the arteria innominata, the size of a small orange. Pericardium filled with fluid. Upper part of right lung symptoms of recent pleurisy. The right subclavian artery was obliterated, and adberent at ligatured part to the first rib. The aneurism had given way just below the ligature of the carotid; the pneumogastric nerve was flattened out on the aneurism. Adhesion of descending aorta to spine, tearing at one point, where a distinct little aneurism, size of a walnut, had corroded the bodies of the tenth and eleventh vertebræ. Lungs were adherent in parts from recent pleurisy, and filled with frothy mucus, but not consolidated. Dura mater adherent in several parts to hemispheres; pia mater opalescent, and evidences of chronic irritation as seen in hard drinkers ; excess of fluid at base of brain. Brain-substance paie and soft. The "posterior communicans" artery on right side obliterated, or rather reduced to a fine fibrons thread. Liver very contracted, with marks of old inflammation on its capsule.

The man survived the operation sixty-five days. I think that, had it not been for his imprudence in exposing himself to the cold night air and setting up the acute attack of pleurisy, he would have survived longer; the paroxysm of cough put more strain on the circulation than the weakened artery could bear. But that he would have lived much longer is very improbable, as there was a spot on the posterior aspect of the aneurism which was as thin as a kid glove, and which would have soon given way. I think the man's life was prolonged by the operation-a questionable benefit. I have no doubt he was spared much suffering, both by the operation and by the use of aconite; for had it been left to nature, the tension and erosion of unyielding tissues would have caused constant severe pain, whereas from the time of the ligature of the arteries the pain was diminished in a marked degree; and the end was certainly a euthanasia in comparison with that which I have seen in other cases of aneurism.

In a younger subject, and with as distinct a diagnosis of innominate aneurism, I should not refuse a similar operation; but the diagnosis as to whether the arterial change is limited to the innominate is difficult-that it should be so limited is improbable.

As far as my experience goes, I believe that chronic alcoholism and syphilis are the two most important causes in bringing about that condition of artery which results in aneurism.

\section{ALCOHOL AS A GENERANT OF THERMO. ELECTRIC CURRENTS IN THE SYSTEM : ONE OF ITS MODES OF ACTION.}

\section{Bx JOHN MULVANY, Staft-Surg. R.N.}

Some years ago, when the application of ice to the spine became popular, I performed a series of experiments for the purpose of ascertaining its mode of action. Commencing on the lower animals, and studying its influence on the bloodvessels of the brain, with the sympathetics integer or interrupted in their continuity, I soon became cognisant of the initiation of thermo-electric currents by thermal disturbance.

Searching for manifestations of electricity in man from a like source, I was obliged to experiment on an individuăl 